\title{
National Policy Objectives and Local Management Results: The Economic, Social, and Environmental Performances of Shellfish-Farming Institutions in the Mont-Saint-Michel Bay (France)
}

Rémi Mongruel* and José A. Pérez Agúndez

Marine Economics Department, Ifremer, UMR Amure, Plouzané, France

*: Corresponding author: R. Mongruel, Tel: +33 2982249 31; Fax: +33 2982247 76; email address: Remi.Mongruel@ifremer.fr

\begin{abstract}
:
This article examines the discrepancies between national policy objectives for the development of shellfish-farming in France and the results of this policy at the local level. National legislation is claimed to favor a "people-oriented" policy and the sustainable use of marine coastal resources. In practice, stakeholders implement this policy under local institutional arrangements. A case study in the Mont-Saint-Michel Bay compares the economic, social, and environmental performances of both mussel and oyster industries. Local management arrangements have avoided overexploitation. Conversely, performances in terms of rent distribution, job retention, and contribution to public budgets are inconsistent with national objectives. This suggests that the existence of conflicting interests, information asymmetries, and unequal bargaining powers was not sufficiently envisaged when the national regulation framework was drafted. However, when combined with an opaque and weakly regulated system of transferable use rights, those factors are likely to influence local management processes and their socioeconomic results.
\end{abstract}

Keywords: aquaculture (shellfish-farming), co-management, institutional economics, policy and decision making, property rights (and institutional arrangements), social change (in coastal areas) 


\section{Introduction}

Among the many roles that national priorities may assign to the development of aquaculture, the provision of job opportunities in coastal areas occupies one of the first places (Bailly and Willmann 2001; Howlett and Rayner 2004; Pillay and Kutty 2005). In Europe, the shellfish farming sub-sector is a relatively old and traditional activity often practised by small and technically simple, family-owned concerns whose role is often significant for local economic development (European Commission 2002). Each production basin may suffer from overexploitation because the cultivated molluscs feed on the natural primary resources of coastal waters which are limited and shared by all producers ${ }^{i}$ (Héral 1990; Raillard and Ménesguen 1994; Nunes et al. 2003). For this reason, shellfish farming raises a commonpool resource (CPR) dilemma that must be addressed through the design of a proper management system.

In France, shellfish farming takes place on the Maritime Public Domain (MPD). The founding of this zone dates back to sixteenth century when the sovereignty of the Crown was extended towards the coasts (Orfila 1990). Because of its legal status, the MPD should be administered by the State in the interest of the entire community. In practice, however, private uses of the coastal zones preceded the establishment of the MPD and use-right owners were traditionally involved in defining and implementing management systems. This scheme applied again when shellfish farming became a significant coastal economic activity during the second half of the nineteenth century (Héral 1990; Mongruel et al. 2008) with the result that, since then, the French shellfish farming sector has been placed under a typical co-management system as defined by inter alia (Plummer and FitzGibbon 2004; Carlsson and Berkes 2005): farmers, government bodies and research institutions share the responsibility of the administration of the resource exploitation from the national level down to the local levels, and together they build this governance system following a continuous problem-solving process. At the national level, the co-management system has led to the establishing of a multi-purpose sectoral policy with the aim of ensuring sustainable use of coastal waters, collective control of the distribution of the resource rent among users and fair contribution to public budgets through land taxation. At the local scale, this policy is implemented by the Marine Culture Commission', which are granted a considerable amount of freedom in designing operational rules and other institutional arrangements.

In theory, co-management is expected to produce positive outcomes such as enhanced equity, efficiency of decision-making, broader based legitimization of actions and increased capacity at a local scale (Plummer and FitzGibbon 2004). Nevertheless, co-management doesn't necessarily eliminate inequities among resource users (Carlsson and Berkes 2005). Moreover, the participation of professional bodies in any decision concerning their activity may hinder the adoption of measures that would benefit the larger national community (Singleton 2000). For instance, aquaculture lobbyists in the Philippines have succeeded in postponing the increase of government leasing fees indefinitely (Primavera 2000), at a time when the shellfish farming land fees in France are considered to be very low (Blanc et al. 1998). Furthermore, it is debatable whether local management arrangements are able to achieve the objectives as defined at the national level. Indeed, the effects of decentralising natural resource governance are strongly dependant on the incentives, complementarities, contradictions and power relationships of the local stakeholders (Bartley et al. 2008).

The purpose of this paper is a better understanding of the institutional failures which may account for the discrepancies between the repeatedly reaffirmed objectives of the national policy regarding shellfish farming development in France and the actual performances of the industry as observed in the local production areas. Following the approach of the new institutional economics applied to natural resources, the aim of our research was twofold (Eggertson 1996): identify the economic drivers that explain how one particular use-right 
regime emerges and examine its implications in terms of economic organisation and performance, such as growth, wealth distribution, and external effects on the environment. Within this theoretical frame, the paper analyses more specifically the mechanisms ruling the distribution of natural resource rent and productivity gains among users, taking into account their broader social and historical context. It tackles the question as to whether or not a trend toward an inequitable distribution of returns and rents may end in the establishing of conflicting interest groups and the deviating of one co-management system from its original objectives.

\section{Materials and Methods}

Common-property institutions and collaborative management have provided an inspiring framework for policymakers seeking to address both environmental and social development goals (Sick 2008). However, a CPR management system will never be successful unless one has defined well-specified use-right regimes and taken into account their embeddedness within wider institutions and particular historical moments with changing power relationships and social choices (Ostrom 1990; Hanna and Munasinghe 1995; Berkes and Folke 1998). A coherence of this nature is often difficult to achieve, particularly when the local management system evolves within the context of a sectoral policy that has been designed at the national level by the state administration and professional representatives with the view of achieving multiple objectives. Depending on stakeholders' perceptions and private interests, economic and social policy objectives may be conflicting. On the one hand, contrary to Hardin's assumption (Hardin 1968), the objective of resource preservation is frequently shared by user groups (Ostrom 1990); on the other hand, they may conflict with the idea that the resource should either support as many jobs as possible (according to a "people-oriented" view of the development policy) or be owned by those who are able to make the most efficient use of it ("efficiency-oriented" development policy). Even if scholars have demonstrated that CPR governance institutions are more robust if and when inequity can be avoided (Berkes and Folke 1998), underlying conflicts among user groups based on their economic status may occur more frequently than generally assumed, especially where traditional exploitation systems are confronted with the intrusion of modern and more intensive exploitation systems (Marshall 2001). This is why it is useful to understand the economic positions and strategies of all stakeholders in order to identify the different sources of inequity and conflicts together with their role in the efficiency of CPR management institutions (Sick 2008).

As a step forward in that direction, we propose to combine an assessment of the global evolution of shellfish farming institutions in France and an in-depth case study of the evolution of this industry's structure, its revenue, and its rent distribution at the local level. The Mont-Saint-Michel (MSM) Bay production area offers the opportunity to compare the somewhat traditional oyster farming sector and the more recent, mechanised, and intensive mussel farming sector. Data and information have been collected from different sources. The analysis of local management rules, arrangements, and decisions in the MSM Bay is based on minutes of the local Marine Culture Commission meetings held between 1987 and 2003 that provide three types of information:

debates related to the spatial planning of shellfish farming spread and related to the exploitation rules for mussel and oyster farming. Both were mainly consensual; the composition of the commission, including the identity of the professional members;

commission decisions regarding the allocating of shellfish farming authorisations and the possible discussions surrounding them. This latter information was compiled into a nominative database of 1,200 recordings, which details the nature and 
The analysis of the economic performance of shellfish-farms is based on two surveys conducted in June 2002 and in May 2004. Based on direct interviews, these surveys focused on two sets of questions dealing with: 1) land structure ${ }^{\text {ii }}$, equipment and labour; 2) production, costs and earnings. Overall, a fairly good coverage of the population was achieved in the survey (Table 1). Various bracket value economic indicators such as labour costs or financial charges were estimated according to pessimistic and optimistic hypotheses.

Table 1. Surveyed sample compared to the global population of shellfish farming farms

\begin{tabular}{|c|c|c|c|c|c|}
\hline & & $\begin{array}{l}\text { Number of } \\
\text { businesses }\end{array}$ & $\begin{array}{c}\text { Including mixed } \\
\text { businesses }\end{array}$ & $\begin{array}{l}\text { Exploited } \\
\text { surfaces* }\end{array}$ & $\begin{array}{c}\text { Production } \\
\text { (tons) }\end{array}$ \\
\hline \multicolumn{6}{|c|}{1 - Pacific Oyster } \\
\hline Population & & 62 & 22 & 314 & 4250 \\
\hline Survey & & 17 & 5 & 114 & 1653 \\
\hline Survey & I & $27.4 \%$ & $22.7 \%$ & $36.3 \%$ & $38.9 \%$ \\
\hline \multicolumn{6}{|c|}{$\begin{array}{l}\text { Population } \\
2 \text { - Blue Mussel }\end{array}$} \\
\hline Population & & 73 & 22 & 272.10 & 10000 \\
\hline Survey & & 21 & 7 & 103.35 & 3757 \\
\hline $\begin{array}{l}\text { Survey } \\
\text { Population }\end{array}$ & I & $28.8 \%$ & $31.8 \%$ & $38.0 \%$ & $37.6 \%$ \\
\hline
\end{tabular}

\section{A Political Retrospective of Shellfish Farming Institutions in France}

The two government decrees of 1852 and 1853 promulgated the modern outlines as to the legal status of the MPD and provided the first definition of shellfish farming use-rights (Beurier 1983). When these decrees were drafted, the French legislators clearly adopted a 'people-oriented' development policy. Indeed, the delivery of shellfish farming authorisations was initially a privilege reserved for the exclusive and personal use of sailors who had joined the navy so that they could benefit from an additional subsistence activity as a compensation for their military duties (Beurier 1983; Dumont 1987). Because of the legal status of MPD, these shellfish farming authorisations should have remained non-transferable. However, a new decree was adopted in 1915, allowing the former owner of a title to indicate his successor for registration by the Administration (Orfila 1990). This derogation to MPD rules led to the emergence of a 'hidden market' in shellfish farming authorisations (Merckelbagh and d'Izarny 1977).

The sector continued thereafter to develop on the basis of this ambiguous legal framework. A national political debate was launched during the 1970s in order to take account of four major changes: the abolition of the registered sailor status in 1967, the industrialisation of shellfish farming, the extension of the market for shellfish farming authorisations, and the need for a better management of coastal waters in the context of increasing space competition (Merckelbagh and d'Izarny 1977; Beurier 1983). The preparatory debate and the consecutive legislation stated the objectives of the shellfish farming development policy. These included promoting the sustainable exploitation of the MPD, ensuring the economic viability of family businesses, and supporting the installation of young entrepreneurs (Beurier 1983). In 1998, these objectives were reaffirmed by a group of auditors commissioned by the French government (Blanc et al. 1998). In addition, this national debate resulted in the two successive government decrees of 1983 and $1987^{\text {iii }}$, which legalised the transfer of use-right authorisations in shell fish farming in the hope that it might be easier to regulate the 
previously hidden market of these transfers. Since this reform, shellfish farming authorisations have virtually turned into individual property rights (Nash 1995; Troadec 2001; Mongruel et al. 2008).

The 1983-1987 decrees led to the founding of the Marine Culture Commission iv (MCC), which is in charge of implementing the national policy in each different production basin. The MCC defines the extent of the production area, its allocation to different cultural practices, and the intensity of operations, aiming at a sustainable use of the resource at the basin level. The allocation of farming authorisations should warrant an income that is sufficient to sustain an average-sized family business and ensure access to shellfish farming land to the greatest majority of professionals (Mongruel et al. 2008; Le Grel and Le Bihan 2009). Four main management tools should enable the MCC to achieve the social objectives of the national policy (Mongruel et al. 2008): a fixed maximal business size should avoid the concentration of use-rights ownership; vacant authorisations should be attributed in priority to young entrepreneurs or small businesses; the MCC is able to prevent the selling of one shellfish farming authorisation when the proposed price appears to be excessively high; and lastly, the annual fees due for the use of the authorisations should reflect their productivity and therefore participate in the control of the possible inflation of use-right prices. Nevertheless, the national legislation framework is still loose in that it does not provide guidelines for the defining of specific objectives in each production basin and allows for a lot of freedom in the designing of local institutional arrangements, including the way the MCC may actually work.

Since the approbation of the current legislation, the shellfish farming sector has deviated from the expected objectives, mainly as regards social goals. Employment has decreased from over 23,000 full-time jobs and 31,000 seasonal jobs in the early 1980 s (Héral 1990) to 10,400 full-time jobs and 7,200 seasonal jobs in 2001 (Girard et al. 2005). However, over the same period of time, no decrease was noticed either in terms of exploited areas $(20,000$ hectares) or in terms of production (100,000 to 120,000 tons of oysters and 60,000 to 70,000 tons of mussels annually ${ }^{v}$ ). The high labour productivity gains were accompanied by significant distributional effects. Indeed, an unintended trend towards industry concentration may have been caused by one major change which occurred between the 1983 and the 1987 decrees.

Stemming from the open preparatory debate, the 1983 decree did away with the "designation-right" of the former owner (inherited from the 1915 decree), and stipulated that each concession put up for sale had to be publicly announced in order to increase competition. This procedure would have allowed the Administration to select buyers according to social criteria. Nevertheless, due to pressure on behalf of the shellfish farmers, this "designation right" was restored a few years later in the decree of 1987. Henceforward, the capacity of Administration to allocate use-rights was restricted to the small number of vacant authorisations. Not surprisingly, a field-survey carried out 20 years later in the Marennes-Oléron basin, the main French oyster production area, established that most of the oyster-farmers in that basin considered that the land-market was globally opaque and prevented small-business owners from acquiring highly productive rights (Mongruel et al. 2008). Thus, the land-market may have favoured economy of scale and productivity gains, while undermining the social goals of the sectoral policy because it is no longer regulated as it had been initially envisaged. 


\section{Shellfish Farming Development in the MSM Bay}

In the MSM Bay, the shellfish farming sector developed following the depletion of the wild oyster fisheries in the 1930s (Héral 1990). The first oyster culture experimentations were undertaken during the second half of the nineteeth century, and oyster farming developed as a modern activity towards the end of the 1940s; mussel farming began around 1954 (Gasquet 1996; Fontenelle 2000). The fluctuating development of oyster-farming is due to disease outbreaks and the introduction of new species. The native species, the European flat oyster (Ostrea Edulis), has been cultivated exclusively in deep-water grounds since 1972. The intertidal area has been entirely dedicated to the Pacific oyster (Crassostrea Gigas) since 1985. At the beginning of the 2000s, the annual production in the bay ranged from $700-$ 1,000 tons of flat oysters ${ }^{\mathrm{vi}}$ and approximately 3,500-4,000 tons of Pacific oysters. Onshore oyster farming is confined to the zones where productivity is the weakest and sedimentation is the highest; it should benefit from the eastward drift of all shellfish farming areas, as experienced by mussel farmers in 2002.

Mussel farming of the blue mussel (Mytilus edulis) is based on bed lines whose length increased from $12 \mathrm{~km}$ in 1954 to $197 \mathrm{~km}$ in 1968. Differences in the farming zones' biological productivity were soon noticed, with a decreasing east/west gradient of productivity. This observation led in 1975 to the transfer of some of the least productive lines located off SaintBenoît-des-Ondes (cf. figure1) to a new production zone located further east. A second partial transfer of existing mussel bed lines to this new zone took place during the early 1980s, and a third transfer was organised in 1984. These transfers yielded significant productivity gains but they were soon weakened by new occurrences of Mytilicola intestinalis (a shellfish parasite) in 1983 and 1984. Producers agreed to lower the stakes in order to reduce the risks of new outbreaks. Following this measure, the development of mussel farming areas in the MSM Bay stabilized, with a total mussel bed line length of 272 kilometres and an average annual production of 10,000 tons (Mongruel and Thébaud 2006). Prior to the latest transfer, which began in 2002, shellfish farming activities in the MSM Bay extended along the coastal zone according to the spatial distribution represented by Figure 1.

Figure 1. Shellfish farming activities in the Mont-Saint-Michel Bay: location until 2002 (Blue mussel) and 2004 (Pacific oyster)

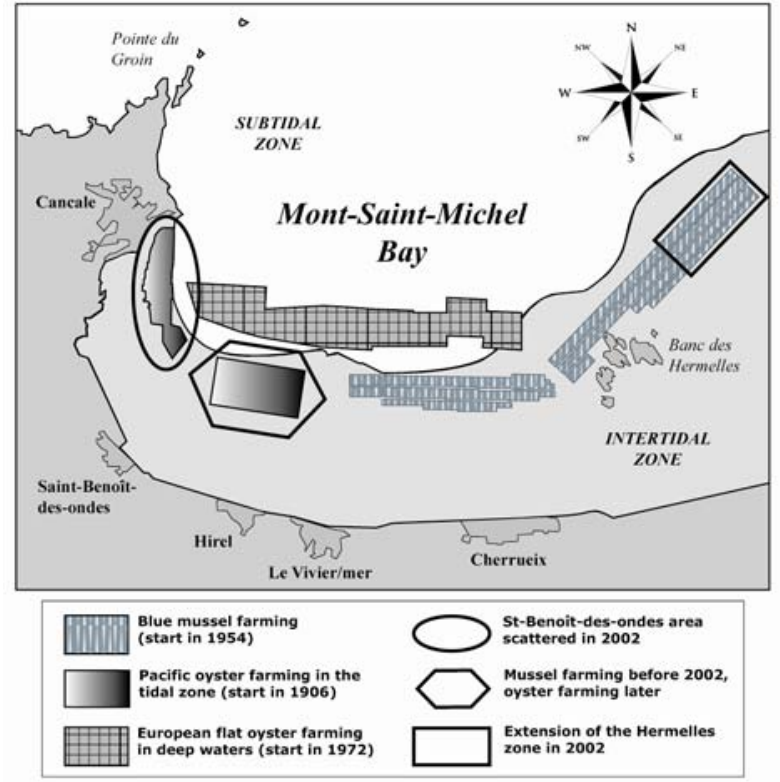


Figure 2 depicts the structural changes in the shellfish-farming sector of MSM Bay ${ }^{\text {vii }}$. At the end of the 1960s, the number of oyster farmers (estimated according to the number of authorisation holders) increased from 400 to 500; this increase was linked to the implementation of a new cultivation technique (oysters were placed in bags laid on tables). This technical innovation temporarily reduced the impact of silting, but eventually the oyster beds, and particularly those located on the coast, were again affected by sedimentation. Due to a deterioration of work conditions that discouraged farmers for whom oyster cultivation was not their only source of income, a high decrease in the number of authorisation holders was observed from 1983 to 1993 . From 1993 to 2004, the number of authorisation holders fell from about 200 to 100 . During the same period, the average turnover per authorisation holder increased twofold, reaching 70,000 Euros per year. This evolution suggests firstly that all the remaining oyster farmers were professionals and secondly, that the sector also benefited from productivity gains.

Figure 2. Number of shellfish-farmers and average turn over per authorisation holder Oyster farming industry in the MSM Bay

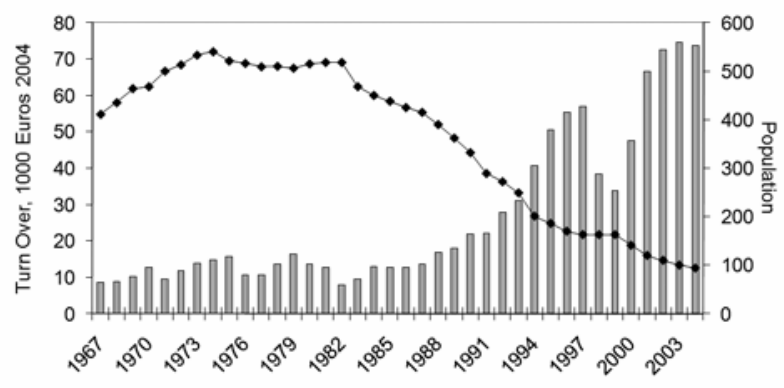

Mussel farming industry in the MSM Bay

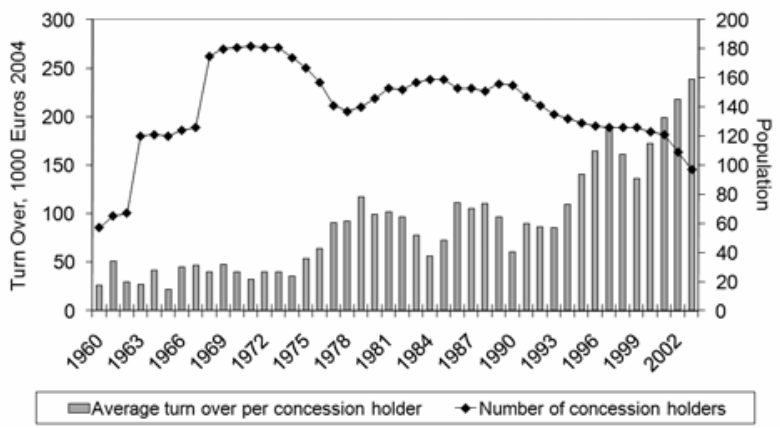

As the mussel-farming zone continued to expand through the end of the 1960s, the number of mussel farmers increased from 57 in 1960 to 180 in 1968. The first significant decrease in the number of authorisation holders occurred between 1972 and 1975, prior to the first transfer towards the east. The subsequent decrease of the average turnover per authorisation holder between 1975 and 1984 may be due to CPR overexploitation (Fontenelle 2000). This hypothesis is coherent with the parasite outbreaks that occurred in 1983 and 1984 because the diseases spread as a result of excessive biomass density. The number of authorisation holders decreased slightly from 155 in 1990 to 126 in 1999, and then fell sharply to slightly under 100 in 2003. In 1999, professionals reached an agreement regarding another transfer of the farms further east round the bay. This latter change in the spatial granting of use-rights led once again to a decrease in the number of farmers, suggesting that any reorganization of a shellfish farming area may lead to a certain amount of merging in the industry. Today, the number of mussel authorisation holders is similar to that of the oyster farming sector, but the average turnover per authorisation holder, which was comparable in the 1960s, is now far higher in the case of mussel farming. Thus, productivity gains have been greater in the mussel farming sector. 


\section{Revenues and Rent Distribution Mechanisms}

This retrospective of shellfish farming development in the MSM Bay demonstrates that a local consensus in favour of ecological objectives has resulted in a collective decrease of exploitation intensity. Nevertheless, unexpected adverse impacts in terms of job losses and revenue concentration indicate that the "efficiency-oriented" policy has surpassed the "people-oriented" policy. This section examines the role that differential productivity gains and the mechanisms which govern the distribution of natural resource rent among users may have played respectively in altering the initial social compromise.

\subsection{Economic Performances of Shellfish Farms}

The average production per business is much higher in the mussel farming sector whereas the average number of workers per company is higher in oyster farming. This means that the physical labour productivity is low in oyster farming (table 2). Nevertheless, the average turnover viii of oyster farms is slightly higher. Thus, natural productivity differentials are almost compensated by product pricingix. The apparent labour productivity (turnover per unit of labour) is 1.5 times higher for mussel farming than it is for oyster farming. On the other hand, the average fixed capital is twice as high in the mussel farming sector. The average added values of the two sectors are relatively close, suggesting that intermediate consumption is similar. Labour costs, however, are much higher in the oyster farming sector due to a more intensive use of the workforce. Thus, the average gross revenue of the oyster farming sector is $50 \%$ lower than that of the mussel-farming sector. The same difference appears when comparing average net profit. Although the net profits are very different, the estimated capital returns for the two sectors are relatively similar, ranging from $7 \%$ to $16 \%$ in the oyster farming sector and from $10 \%$ to $15 \%$ in the mussel farming sector ${ }^{x}$.

Table 2. Average financial results per farm in each sector, under low and high hypothesis

\begin{tabular}{lrrrr}
\hline & \multicolumn{2}{c}{ Oyster Farming } & \multicolumn{2}{c}{ Mussel Farming } \\
\cline { 2 - 5 } & $\begin{array}{l}\text { pessimistic } \\
\text { hypothesis }\end{array}$ & $\begin{array}{c}\text { optimistic } \\
\text { hypothesis }\end{array}$ & $\begin{array}{c}\text { pessimistic } \\
\text { hypothesis }\end{array}$ & $\begin{array}{c}\text { optimistic } \\
\text { hypothesis } \\
\text { Production }\end{array}$ \\
Number of Workers & 57 tons & & 179 tons & \\
Capital Total (current value) & $267424 €$ & & 3.7 & \\
Turnover (TO) & $321072 €$ & & $551616 €$ & \\
Labour Productivity to TO & $53993 €$ & & $301228 €$ & \\
Added Value & $233042 €$ & $255451 €$ & $256085 €$ & $256085 €$ \\
Gross Exploitation Revenue & $66461 €$ & $77283 €$ & $140882 €$ & $158955 €$ \\
Net Profit & $18721 €$ & $42576 €$ & $53055 €$ & $80349 €$ \\
Return on Capital & $7.0 \%$ & $15.9 \%$ & $9.6 \%$ & $14.6 \%$ \\
\hline
\end{tabular}

The higher profitability of mussel farming is essentially due to the investments (amphibious boats, harvesting machines, etc.) which are more capital intensive in this sector and lead to a higher labour productivity. As labour costs are comparable in both sectors, the profitability of each labour unit is much higher in the mussel farming sector. The mussel farming production system is based on a combination of capital and labour, which minimizes labour costs and generates a higher average net profit per company. Basically, this is due to shorter production cycles and the mechanisation of certain tasks (Mongruel and Pérez Agúndez 2006). This latter aspect points to the notion of natural productivity differentials. Indeed, although average net profits are significantly different in the two sectors, returns on capital 
are similar because only half as much capital is used in the oyster farming sector. In particular, the fixed capital for equipment in oyster farming businesses is 1.6 times lower than that of mussel farming businesses (200,000 € per oyster farm versus $320,000 €$ for mussel farms. Regarding land, the fixed capital in oyster farming businesses is again 3.5 times lower $(66,000 €$ per business versus $230,000 €)$. As to the composition of this fixed capital, land value amounts to $25 \%$ of the total in the oyster-farming sector and up to $42 \%$ in the musselfarming sector. The higher expectations of net profit in the mussel farming sector appear to have been transferred into a higher valuation of mussel farming authorisations, which accounts for the fact that the returns on capital are finally similar in the two sectors.

\subsection{Net Profits and Leasing Fees}

Individual use-rights for shellfish farming are subject to the payment of annual fees, which can be considered as the means by which the Administration tries to extract all or part of the rent of public resources (Troadec 2001). The annual land fees for the use of shellfish farming authorisations have been established by a ministerial order following the government decree of 1987. The annual fees consist of a lump-sum plus an amount that varies in relation with the location and the use for which the authorization has been given. Nevertheless, no provision was made in the decree for these fees to be reviewed, even in the case of specific changes in operating conditions. The result of this is that these fees have remained unchanged since 1988. Thus, it is uncertain whether the resource rent collection from shellfish farming activities in the MSM Bay is appropriate or not. Although all production factors tend to point toward comparable levels of cost in both sectors, the net profit per business is much higher in the mussel-farming sector. This would suggest that the trophic resources of the bay generate a higher net rent when used by mussel farms than when used by oyster farms. However, an appropriate taxation system should reflect the profitability differentials between technical practices (Dumont 1987). If not, this would mean in our case that some of the resource rent is kept by mussel-farmers without due cause, while oysterfarmers and the society are worse off.

This issue may be addressed through the procedure of the multiple objective benefit analysis. This method basically consists of estimating the net returns to each user group by unit of exploited surface, thus allowing for comparison (Nickerson 1999). In the present analysis, we have estimated the value per unit of exploited surface area of the turnover, net profit, leasing fees, and land value ${ }^{\mathrm{xi}}$ (table 3 ). Our estimations confirm that the economic parameter on which the land fees are based is the farm's turnover, as the fees expressed in percentage of the expected turnover are comparable if not similar in both sectors (they are 2 to 3 times higher in the oyster-farming sector). But when the fees are expressed as a percentage of the expected net profit, they are 5 to 10 times higher in the oyster-farming sector. If the taxation system had been based on profitability differentials, the rates would not have been so unequal. In addition, the fees as expressed as a percentage of the land prices are also ten times lower in the mussel-farming sector. This demonstrates that land value, which reflects the expected profitability of each activity, could be used to establish more appropriate fees.

Table 3. Fees and economic performances per unit of exploited surface

\begin{tabular}{|c|c|c|c|c|}
\hline \multirow[b]{3}{*}{ Annual Fees* } & \multicolumn{2}{|c|}{$\begin{array}{l}\text { Oyster Farming } \\
\text { (€/ha and \%) }\end{array}$} & \multicolumn{2}{|c|}{$\begin{array}{c}\text { Mussel Farming } \\
(€ / 100 m \text { and \%) }\end{array}$} \\
\hline & $\begin{array}{c}\text { optimistic } \\
\text { hypothesis }\end{array}$ & $\begin{array}{l}\text { pessimistic } \\
\text { hypothesis }\end{array}$ & $\begin{array}{l}\text { optimistic } \\
\text { hypothesis }\end{array}$ & $\begin{array}{l}\text { pessimistic } \\
\text { hypothesis }\end{array}$ \\
\hline & $185 € / h a$ & $231 € / h a$ & $9.91 € / 100 \mathrm{~m}$ & $9.91 € / 100 m$ \\
\hline Annual expected Turnover & $47879 € /$ ha & $47879 € /$ ha & $6121 € / 100 m$ & $6121 € / 100 m$ \\
\hline
\end{tabular}




\begin{tabular}{lrrrr}
\hline Annual expected Net Profit & $6349 € /$ ha & $2792 € /$ ha & $1633 € / 100 \mathrm{~m}$ & $1078 € / 100 \mathrm{~m}$ \\
Land prices & $13202 € / \mathrm{ha}$ & $13202 € / \mathrm{ha}$ & $7470 € / 100 \mathrm{~m}$ & $7470 € / 100 \mathrm{~m}$ \\
Fees \% Turnover & $0.39 \%$ & $0.48 \%$ & $0.16 \%$ & $0.16 \%$ \\
Fees \% Net Profit & $2.91 \%$ & $8.27 \%$ & $0.61 \%$ & $0.92 \%$ \\
Fees \% Land Prices & $1.40 \%$ & $1.75 \%$ & $0.13 \%$ & $0.13 \%$ \\
\hline
\end{tabular}

*: in the case of oyster-farming, annual fees may increase by $25 \%$ depending on the cultivation practice.

\subsection{Land Market}

From 1988 to 2003 (figure 3), the average value of oyster-farming authorisations collapsed from over 22,000 to around 13,000 Euros/ha, excluding a brief reversal of the trend in 1999 coinciding with a speculative phenomenon. At the same time, mussel farming authorisations increased from 5,000 to 8,000 Euros/100 meters with the highest prices being reached in 2000. Higher mussel farming profitability has thus led to higher land prices.

Figure 3. Land prices in the shellfish farming area, Mont-Saint-Michel Bay 1988-2003

Oyster farming land prices
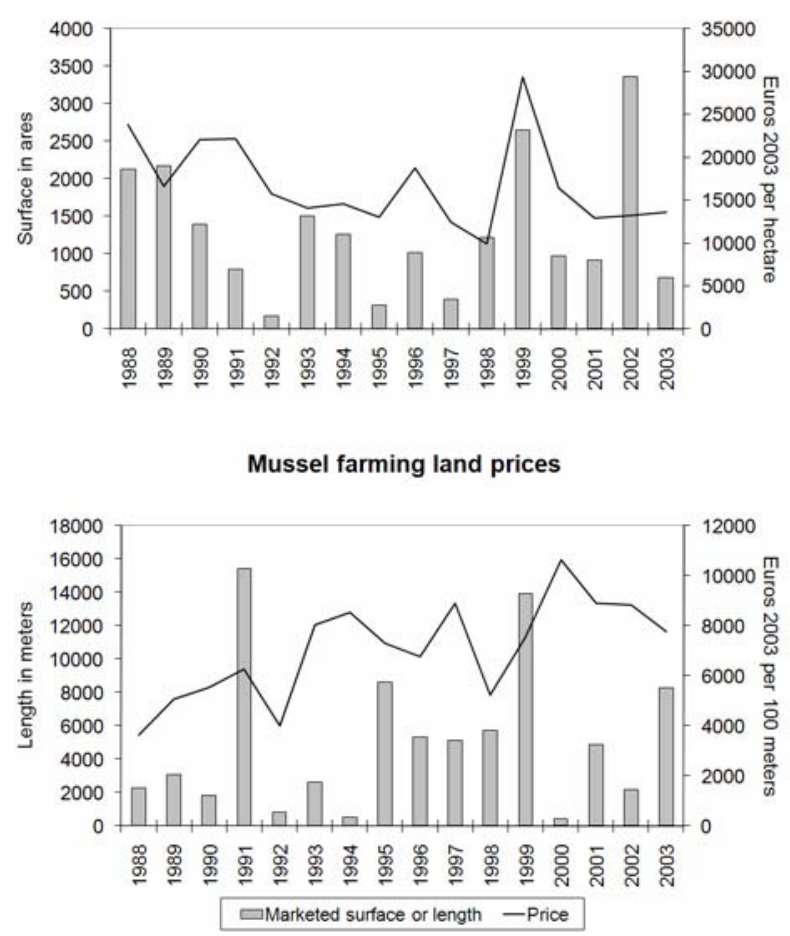

These results confirm what economists had predicted when the law was changed in 1987.Allowing for the paid transfer of marine culture authorisations: in the absence of a proper revaluation of annual fees, the introduction of a land market in the MPD would lead to a capitalisation of most of the resource rent into the land prices (Dumont 1987). Thus, the first-time sellers of mussel farming authorisations were able to capture a bigger share of the resource rent as compared to other producers. In addition, high land value or very unstable prices make it difficult for new producers to set up companies, especially if they are young. These arguments should justify more appropriate and possibly variable annual fees, which would prevent speculative behaviours and do away with entry barriers when new producers are needed in order to strengthen competition. 
Local institutional arrangements are therefore unable to actually control the concentration of the shellfish farming industry $\mathrm{xii}$. Indeed, in addition to the problem of increasing or unstable land prices, the fixed maximal business size would be compatible with a distribution of the land to no more than 10 oyster farms and 6 mussel farms, yet a hundred businesses are still operating in the MSM Bay. Thus, it is of no surprise to note that the land allocation system actually tends to increase the concentration of the industry for three different reasons (Mongruel et al. 2008). Firstly, the vacant authorisations attributed by the Administration account for less than $10 \%$ of the total surfaces whose ownership has changed hands between 1987 and 2003. Secondly, whereas the transfers of authorisations within a family tend to maintain the number of beneficiaries over time, on the land market, the buyers of authorisations were only half as many as the sellers (one hundred against approximately two hundred). Thirdly, some farmers appear to have adopted speculative behaviours following the latest restructuring of the shellfish farming area. This general trend indicates productivity gain expectations of farmers from this new spatial organisation. This is particularly true as regards the oyster farming authorisations, whose value increased three-fold between 1998 and 1999. Indeed, one crucial aspect in this restructuring would be the conditions according to which some authorizations attached to the possible abandoned zones in the old oyster farming area were going to be transformed into access rights in the more productive new zones. Nevertheless, it is doubtful that all the people in the shellfish farming community benefited from the same level of information when the negotiations between the public authorities and the professional representatives began and this information asymmetry may have encouraged opportunistic strategies regarding land acquisitions.

\section{Discussion}

Although the French shellfish farming policy is multi-purpose, its local implementation turns out to be more narrowly focused. Local management aims mainly at avoiding resource overexploitation (Le Grel and Le Bihan 2009), but it neglects distributional issues and their social consequences (Mongruel et al. 2008). This is coherent with the fact that the Marine Culture Commission requires scientific advice exclusively regarding eco-physiological and sanitary assessments. In the MSM Bay, shellfish farmers have agreed upon collective management actions driven toward global economic efficiency. However, as regards employment, family-business protection and land price control, the performances of the sector stand far from national policy expectations.

The hope for a good governance of shellfish farming activities in France was based on three assumptions. Firstly, the enforcement of an explicit use-rights market, which the Administration could supervise, was expected to prevent the constitution of powerful private economic entities on the Maritime Public Domain. Secondly, the 'people-oriented' sectoral policy was expected to perpetuate the cooperative model of the family-scale businesses. Lastly, the inclusion of professional representatives within the MCCs was expected to ensure the defence of the interests of the shellfish farming sector as a whole. However, a community-based management system is also a social process from which political coalitions may emerge in a context of information and bargaining power asymmetries: differences within a community lead people to search for strategic advantages toward the control of resources and economic gains from institutional change (Knight 1992). In such situations, powerful minorities are able to impose management rules and institutional arrangements for their own interests. In addition, traditional farmers are not equal in their ability to adopt technical and commercial innovations and rapid changes may notably affect the current social collective consensus, many aspects of which often remain implicit. Such eventualities, which should be considered normal, were not anticipated when the French national regulation framework for shellfish farming was drafted. But ignoring the internal discrepancies within the industry has turned out to be ineffective because "conflict stemming 
from diversity of interests and/or perceptions, if left unchecked, can lead to institutional breakdown" (Sick, 2008).

The causes for the failure of shellfish farming institutions in France are twofold. At the national level, the rapid transformation of the transparent and centralised use-right market planned with the 1983 decree into the decentralised market established by the 1987 decree has deprived the Administration of many of its redistributive tools. In any co-management regime, the competent State agency may be captured by private interests and abandon the defence of the public interest, especially when symbiotic relationships have developed between the elected officials and the professional representatives, and when public participation to the decision-making process is limited (Singleton 2000). It is noteworthy that the 1983 decree was promulgated after a long and open consultation, while the 1987 decree was adopted by a government known to be very close to high-level professional representatives, shortly after the political majority changed in 1986. At the local level, technical innovations have resulted in the emergence of more efficient exploitation systems which have lead to an alteration of the social compromise. On the one hand, each time userights have been re-allocated through a process of transparent negotiation, shellfish farmers of the MSM Bay have acted as if they were perfectly aware of the fact that the implicit shared interest of the CPRs users tended towards an equitable distribution of use-rights: the access to a new production area has always been granted first to the owners of less productive userights (Mongruel and Thébaud 2006). On the other hand, the daily functioning pattern of the allocation system has remained dominated by the weakly regulated use-rights market: under that more opaque institution, the individualistic motivations, the financial power disparities and the information asymmetries entail altogether the industry structure towards more concentration (Mongruel et al. 2008).

It is difficult to assess the profitability of shellfish farming activities as it depends on numerous factors including natural productivity, technological efficiency, and labour organisation. In France, however, land taxation is kept separate from the evolution of land value, which can be considered as the best indicator of real productivity. Land taxes remain insufficient to adequately collect the rent from the public natural resource and to hinder land price inflation. As a result, economic powerful entities have been able to consolidate and act toward the prevalence of the "efficiency-oriented" development policy. Cross-checking with other information sources, including professional newspapers, has demonstrated that wealthy farmers, owners of the largest businesses of the basin and proponents of intensive technologies, have succeeded in monopolizing professional representative nominations to the Marine Culture Commission. Since most of these representatives are also heads of local trade unions, they benefit from a high political influence which enables them to take the lead in the negotiating of local rules. The apparent consensus for a fair initial allocation of userights could have been all the more easily supported by the proponents of the "efficiency criteria" as they knew besides that the land-market would give them the opportunity to buyback these concessions at a later date. Be it opportunistic or deliberate, this strategy has become possible as a result of the weak intervention on behalf of the local Administration, which, for three different reasons, has been deprived of real bargaining power. Firstly, the local managers had no clear 'specific objectives' that would have helped them to pursue the 'general objectives' of the national policy, and especially the social objectives. Secondly, intervention means of these managers were ineffective, especially regarding market control. Thirdly, they were not used to asking social scientists for their advice and expertise in assessing the evolution of local institutions and their consequences. The revealing of some of the causes of the dysfunction of the French shellfish farming co-management system demonstrates that further attention should be paid to the relations between the evolution of the social and economic status of user groups and the design of management institutions in the aquaculture sector. 


\section{Acknowledgements}

This article is based on the results of two successive research projects funded by the French National Program for Coastal Environment (PNEC) and the LITEAU Program of the French Ministry of Environment (MEEDDM). The authors want to acknowledge Patrick Le Mao, head of the Ifremer Station at Dinard, for his support during the infield investigations, Aurore Davaine and Manuelle Philippe, who participated to the surveys, and Séverine Julien who realised the graphical works. We are grateful for helpful comments and insightful suggestions from three anonymous reviewers.

\section{References}

Askenazy, P. 2003. Partage de la valeur ajoutée et rentabilité du capital en France et aux Etats-Unis: une réévaluation. Added value distribution and capital profitability in France and in the USA: a re-assessment. Economie et Statistiques n 363-364-365: 167-189.

Bailly, D. and R. Willmann. 2001. Promoting sustainable aquaculture through economic and other incentives. In Aquaculture in the third millennium, eds. R. P. Subasinghe, M. J. Phillips, P. Bueno, C. Hough, S. E. McGladdery and J. R. Arthur, 95-101. Technical Proceedings of the Conference on Aquaculture in the Third Millennium, Bangkok, Thailand, 20-25 February 2000. Rome: NACA, Bangkok and FAO.

Bartley, T., K. Andersson, P. Jagger and F. Van Laerhoven. 2008. The contribution of institutional theories to explaining decentralization of natural resource governance. Society and Natural Resources 21(2): 160-174.

Berkes F. and C. Folke (eds.). 1998. Linking social and ecological systems: management practices and social mechanisms for building resilience. Cambridge, UK: Cambridge University Press.

Beurier, J.-P. 1983. De la conchyliculture aux cultures marines : étude du décret du 22 Mars 1983 sur les exploitations de cultures marines. From shellfish farming to marine cultures: analysis of the 22 March 1983 Decree on marine culture exploitations. Revue Juridique de l'Environnement 4: 323-329.

Blanc, F., P. Silberzahn, and L.-J. Sourd. 1998. Mission d'audit de la conchyliculture : rapport de diagnostic et de propositions. Audit of the shellfish farming sector: diagnosis and proposition report. Paris : Ministère de l'Agriculture et de la Pêche.

Carlsson L. and F. Berkes. 2005. Co-management: concepts and methodological implications. Journal of Environmental Management, 75(1): 65-76.

Dumont, P., 1987. Utilisation du Domaine Public Maritime par l'ostréiculture et problèmes de tarification. Use of the Maritime Public Domain by oyster farming and taxation problems. Cahiers d'Économie et Sociologie Rurales 4: 45-66.

Eggertson, T. 1996. The economics of control and the cost of property rights. In Rights to nature: Ecologic, economic, cultural and political principles of institutions for the environment, eds. S. S. Hanna, C. Folke, and K. Maler, 157-178. Island Press.

European Commission, 2002. A strategy for the sustainable development of European aquaculture. Communication from the Commission to the Council and the European Parliament, COM(2002) 511 final. Brussels, Belgium.

Fontenelle G., 2000. Dynamiques de cogestion : un problème, plusieurs solutions ; cas de la baie du Mont-Saint-Michel, France. Co-management dynamics: one problem, several 
solutions; the case of the Mont-Saint-Michel Bay, France. Revue de l'Université de Moncton, hors série, 19-45.

Gasquet, R. 1996. Historique et évolution de la conchyliculture dans la baie du Mont-SaintMichel. History and development of shellfish farming in the Mont-Saint-Michel Bay. Master's thesis, Department of Animal Supply Chains, AgroParisTech. Paris, France.

Girard, S., J. A. Pérez Agúndez, L. Miossec, and N. Czerwinski. 2005. Recensement de la conchyliculture 2001. Shellfish Farming Census 2001. Agreste Cahiers $n^{\circ} 1$. Paris, France: Ministère de l'Agriculture, de l'Alimentation, de la Pêche et de la Ruralité.

Hanna, S. and M. Munasinghe (eds.). 1995. Property rights and the environment: Social and ecological issues. Washington D.C.: Beijer International Institute of Ecological Economics and The World Bank.

Hardin, G. 1968. The Tragedy of the Commons. Science 162(3859): 1243-1248.

Héral, M. 1990. Traditional oyster culture in France. In Aquaculture, Volume 1, ed. G. Barnabé, 342-387. London, UK: Ellis Horwood.

Howlett, M., and J. Rayner. 2004. (Not so) smart regulation"? Canadian shellfish aquaculture policy and the evolution of instrument choice for industrial development. Marine Policy 28(2): 171-184.

Knight, J. 1992. Institutions and social conflicts. Cambridge, UK: Cambridge University Press.

Le Grel, L. and V. Le Bihan. 2009. Oyster farming and externalities: the experience of the bay of Bourgneuf. Aquaculture Economics and Management 13(2): 112-123.

Marshall, J. 2001. Landlords, leaseholders \& sweat equity: changing property regimes in aquaculture. Marine Policy 25(5): 335-352.

Merckelbagh, A. and A. d'Izarny. 1977. Propositions de gestion des espaces maritimes. Management proposals for maritime areas. Recherche Sociale 62: 22-50.

Mongruel, R., J. A. Pérez Agúndez, and S. Girard. 2008. Droits à produire transférables : le marché des concessions conchylicoles et ses effets non désirés. Transferable rights to produce: the market for shellfish farming concessions in France and its unintended effects. Économie Rurale n 306: 23-38.

Mongruel, R. and J. A. Pérez Agúndez. 2006. Comparing economic dynamics of oyster and mussel farming, with particular emphasis on their profitability: an application in the MontSaint-Michel Bay (France). Proceedings of the XIII ${ }^{\text {th }}$ Biennial Conference of the International Institute of Fisheries Economics and Trade, 11-14 July 2006. Portsmouth, UK: CEMARE.

Mongruel, R. and O. Thébaud. 2006. Externalities, institutions and the location choices of shellfish producers: the case of blue mussel farming in the Mont-Saint-Michel bay (France). Aquaculture Economics and Management 10(3): 163-181.

Nash, C. E. 1995. Aquaculture sector planning and management. Cambridge, MA: Fishing News Books.

Nickerson, D. J. 1999. Trade-offs of mangrove area development in the Philippines. Ecological Economics 28(2): 279-298.

Nunes, J.P., Ferreira, J.G., Gazeau, F., Lencart-Silva, J., Zhang, X.L., Zhu, M.Y., and Fang, J.G., 2003. A model for sustainable management of shellfish polyculture in coastal bays. Aquaculture 219(1-4): 257-277.

Orfila, G. 1990. Droit de la conchyliculture et de l'aquaculture marine. Law of shellfish farming and marine aquaculture. Saint-Jean-d'Angely, France: Éditions Bordessoules.

Ostrom, E. 1990. Governing the commons. Cambridge, UK: Cambridge University Press. 
Pillay, T. V. R. and M. N. Kutty. 2005. Aquaculture: principles and practices. Oxford, UK: Blackwell Publishing.

Plummer, R. and J. FitzGibbon. 2004. Co-management of natural resources: a proposed framework. Environmental Management 33(6): 876-885.

Primavera J. H. 2000. Development and conservation of Philippine mangroves: institutional issues. Ecological Economics 35(1): 91-106.

Raillard, O. and A. Ménesguen. 1994. An ecosystem box model for estimating the carrying capacity of a macrotidal shellfish system. Marine Ecology, Progress Series 115: 117-130.

Sick, D. 2008. Social contexts and consequences of institutional change in common-pool resource management. Society and Natural Resources 21(2): 94-105.

Singleton, S. 2000. Co-operation or capture? The paradox of co-management and community participation in natural resource management and environmental policy-making. Environmental Politics 9(2): 1-21.

Troadec, J.-P. 2001. The regulation of access to natural resources in marine aquaculture. In Modern aquaculture in the coastal zone, ed. J. Coimbra, 1-19. IOS Press.

\section{Notes}

\footnotetext{
'Any increase of cultivated biomass may reduce the food available to individuals and generate negative effects on total production due to a plummeting growth rate or a higher occurrence of diseases and mortality crisis.

ii The land structure is equivalent to total superficies (for oyster) or total length (for mussel bed-lines) of the shellfish farming authorisations belonging to the company.

iii Decree $n^{\circ} 83-228$ of 22 March 1983, amended by decree $n^{\circ} 87-756$ of 14 September 1987.

iv These commissions consist in an equal number of professionals and Administration representatives.

${ }^{v}$ All production volumes are in metric tons.

vi Due to the limited annual production and small number of businesses involved in this activity (8 businesses in 2004), the European flat oyster sector was not included in the analysis.

vii These estimates are based on the data provided by the Administration (Maritime Affairs Delegation in Ille-et-Vilaine) and on shellfish price time-series (Ofimer annual reports on French seafood markets).

viii Average turnovers per company in each sector are much higher than those observed through the estimates presented in Section 3 because the survey provided data per farm, which are less numerous than the authorisations holders. In addition, the samples over-represent large businesses.

${ }^{\text {ix }}$ The average prices paid to the producers amounted to $3.2 € / \mathrm{kg}$ for oysters and to only $1.6 € / \mathrm{kg}$ for mussels (Mongruel and Pérez Agúndez, 2006).

${ }^{x}$ The net return on capital has been estimated to be around $17 \%$ for the agro-industry in France during the 1990s (Askenazy, 2003). No data is available for agriculture, even if the return on capital is probably lower in this sector.

${ }^{x i}$ The average land value was estimated according to the prices of farming authorisations during the years 1999-2001 for mussel farms and 2002-2003 for oyster farms.

xii In $2002,50 \%$ of the oyster farms owned $74 \%$ of the use-rights and $50 \%$ of the mussel farms owned $80 \%$ of the use-rights.
} 